\title{
ConclavE 2016
}

The Department of Conservative Dentistry and Endodontics, Tamil Nadu Government Dental College and Hospital, Chennai, India, organized a community development education program titled ConclavE 2016 on full mouth rehabilitation in association with the Conservative and Endodontic Association of Tamil Nadu and the Indian Association of Conservative Dentistry and Endodontics (IACDE) on December 15, 2016. The organizing committee of this institution had prepared a dynamic scientific program and presented an impressive roster of highly reputed speakers to lead it.

Key speakers for the day, Dr B Mohan, General Secretary of IACDE, delivered a valuable practical insight on "full mouth rehabilitation." Dr Kavitha Sanjeev, Professor, SRM Dental College and Hospital, Chennai, India, delivered a focused lecture on "ceramics and cementation procedure." Dr RS Mohan Kumar, Joint Secretary, IACDE, spoke on "Cention N," a contemporary posterior restorative material.

This was followed by live demonstration by $\mathrm{Dr} B$ Mohan on centric relation recording and prototype restoration.

This CDE program was attended by 200 delegates from various institutions and private practitioners across Tamil Nadu. This program served as a platform for the exchange of clinical and scientific knowledge on the emerging challenges and latest developments in full mouth rehabilitation.
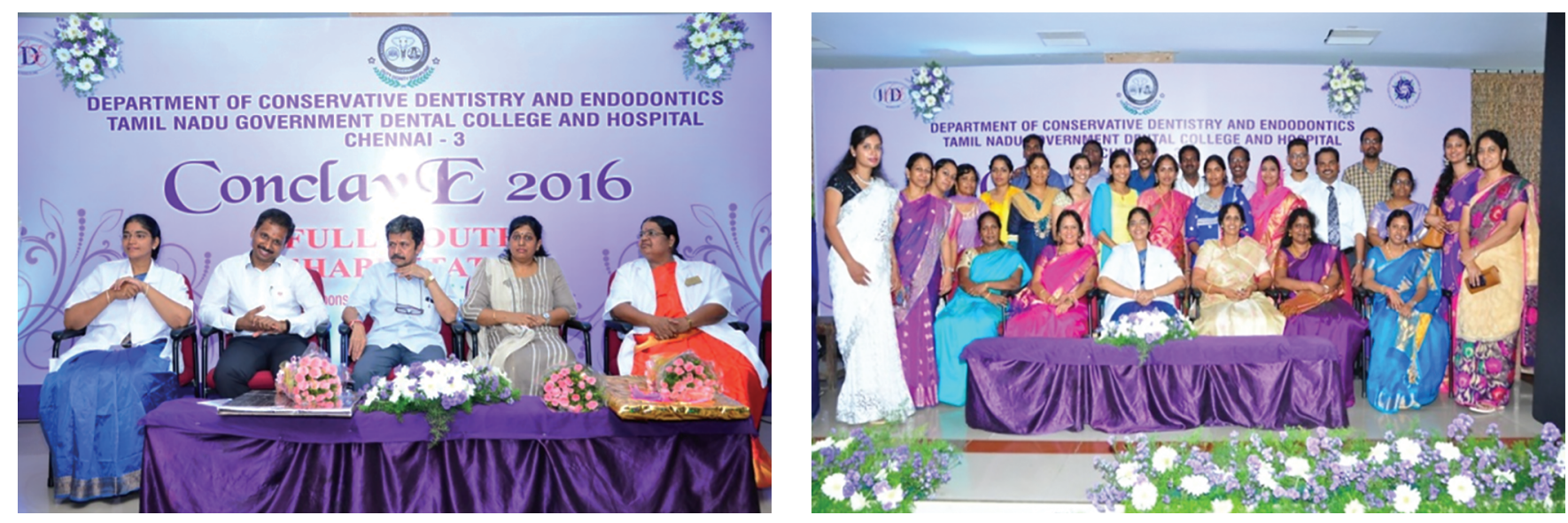

M Kavitha

Professor and Head (Organizing Chairman) Department of Conservative Dentistry and Endodontics Tamil Nadu Government Dental College and Hospital Chennai, Tamil Nadu, India 